Volume 7

Issue 3 May

Article 5

May 1980

\title{
The Paradoxes of Health Planning
}

Bonnie Morel Edington

New Jersey Department of Health

Follow this and additional works at: https://scholarworks.wmich.edu/jssw

Part of the Clinical and Medical Social Work Commons, Health Policy Commons, and the Social Work Commons

\section{Recommended Citation}

Edington, Bonnie Morel (1980) "The Paradoxes of Health Planning," The Journal of Sociology \& Social Welfare: Vol. 7 : Iss. 3 , Article 5.

Available at: https://scholarworks.wmich.edu/jssw/vol7/iss3/5

This Article is brought to you by the Western Michigan University School of Social Work. For more information, please contactwmu-scholarworks@wmich.edu.

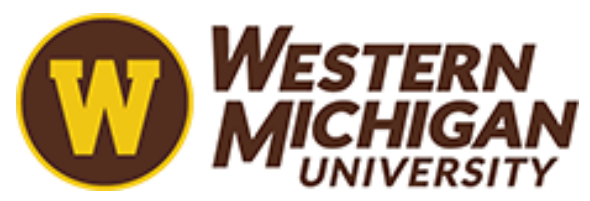


THE PARADOXES OF HEALTH PLANNING

\author{
Bonnie Morel Eaington \\ Health Planning Services \\ New Jersey Department of Health
}

The National Health Planning Act of 1974 designated 200 health Systems Agencies (HSAs) nationally and a State Health Planning and Development Agency in each state. Components of the law are analyzed to illustrate its ambiguities and contradictions. The components analyzed are: the findings which led to the passage of the law; the law's purpose; the ten national health priorities; the National Guidelines for Health Planning; the purposes of the HSAs and the data they are to assemble and analyze. The major contradiction is that agencies designated to focus on cost containment in health care are expected to make health care services more accessible and acceptable, and improve their quality. These agencies are also expected to improve the health of the population, including ill health attributable to environmental factors.

Social policy regarding prevention is discussed, particularly the current trend toward blaming the victim. Contradictions and ironies in planning for cost containment are also pointed out: patients are blamed for utilization that is provider-induced; there is no constituency for cost containment; consumers (i.e., purchasers) with the greatest potential clout are large employers and organized labor, but such labor-management coalitions are just beginning to be developed; Certificates of Need require no proof of need; and current anti-regulation fervor may not distinguish state health planning regulations for cost containment, such as those adopted in New Jersey, from the cost-generating regulations of most government agencies. 
The National Health Planning and Resources Development Act of 1974 designated a State Health Planning and Development Agency in each state, and 200 local Health Systems Agencies (HSAs) to plan for discrete areas that blanketed the country. The law also established a Statewide Health Coordinating Council whose members are appointed by the Governor, 60\% of these appointees being nominated by the HSA, and at least half being non-providers of health care. Each HSA produces a plan, and the council, staffed by the state planning agency, compiles these into a state Health Plan.

The law has been called one of the most complex pieces of modern legislation and it gives HSAs conflicting and contradictory mandates. In its "Findings and Purpose" section it states first that "equal access to quality health care at a reasonable cost is a priority of the Federal Government", then goes on to say that: the "massive infusion of Federal funds into the existing health care system has contributed to inflationary increases in the cost of health care and failed to produce an adequate supply or distribution of health resources", which has inhibited equal access; there are inadequate incentives for the use of appropriate alternatives to inpatient care; and "large segments of the public are lacking in basic knowledge regarding proper personal health care and methods for effective use of available health services".

There is a section in the law on the ten national health priorities: (1) provision of primary care services for the medically underserved; (2) coordination and consolidation of hospital services; (3) development of group practices and health maintenance organizations (HMOs); (4) increased use of physician assistants; (5) coordination and consolidation of hospital support services; (6) improvement in the quality of health services; (7) geographic integration of levels of care; (8) prevention of disease; (9) improvement of hospital management procedures; and (10) effective health education for the public.

There is also a section on national guidelines for health planning, which states that within eighteen months of the passage of the law, guidelines were to be issued concerning national health planning policy. The guidelines were to be of two types: standards for the appropriate supply, distribution, and organization of health resources; and a statement of national health planning goals expressed in quantitative terms, the goals to be developed after considering the national health priortties. The law was signed January 4, 1975, and, as of September, 1979, only one document with eleven standards had appeared in final form, March 28, 1978, fifteen months behind schedule.

These National Health Planning Guidelines specified: maximum numbers of beds in ratio to population for the three major types of hospital services -- general medical-suxgical, obstetric, and pediatric; 
minimum occupancy levels in those services; and minimum numbers of specialized procedures (e.g., obstetrical deliveries, open heart surgery, and CAT scans) to be done at a single site.

The standards for maximum numbers of beds are intended to prevent resource duplication and thereby restrain costs. The standards regarding minimum numbers of procedures are intended not only to prevent duplication and restrain costs, but also to encourage consolidation of services so that adequate utilization, quality of care and, to some degree, health can be improved. The standards were based on well-established research findings and recommendations by the appropriate medical professional organizations. Data indicate that as the numbers of procedures increase, including routine obstetrical procedures, the mortality rate among patients declines, since the medical team gains proficiency.

The law states that the HSAs are to do their planning for seven purposes: (1) to improve health; (2) to increase the accessibility of health services; (3) to increase the acceptability of health services; (4) to increase the continuity of health services; (5) to increase the quality of health services; (6) to restrain costs; and (7) to prevent unnecessary duplication of services.

The law then states that the HSAs are to "assemble" and analyze data on the health of the population, the health care delivery system, the effect the health care delivery system has on the health of the population, and the environmental and occupational exposure factors affecting the health of the population. But it also states they are not to collect data, they are to use existing data.

The law instructs the HSAs to consider the national priorities, the national guidelines, and the pre-existing data in preparing their plan, which is to "describe a healthful environment and health system which, when developed, will assure that quality services ... Iarel available and accessible in a manner which assures continuity of care, at reasonable cost, for all residents of the area...."

The chart on the following page is an analysis of the degree of overlap between and among: the factors that surfaced in the findings that led to the law; the national health priorities; the HSAs' purposes as stated in the law; the type of data HSAs are supposed to assemble and analyze; and the National Fealth Planning Guidelines. The diagram illustrates a major ambiguity in the law - are planners being paid primarily to control costs or to improve health?

As can be seen in the first column of the diagram, none of the findings that led to the law were directly related to the health of 
362

Findings were related to

Inaccessibility
National Bealth

Priorities

1) Primary care for medically underserved

4) Increased use of physician assistants

2) COORDIN./CONSOLID. OF HOSP. SERVICES

3) Development of group practices/HMOs

INFLATIONARY COSTS*

4) Increased use of physician assistants

5) coordin./consolid. of support services

7) Geog. integration of levels of care

8) Prevention

9) Improvement of hosp. mgt. procedures

1) Primary care for medically underserved

MALDISTRIBUTION OF RESOURCES

2) COORDIN. / CONSOLID. OF HOSP. SERVICES
4) Increased use of physician assistants

7) Geog. integration of levels of care

3) Development of group

Need for

incentives for

alternatives to

inpatient care

Need for health

education of

public practices/HMOs

\section{8) Prevention}

8) Prevention

10) Effective health educ. of public

\begin{tabular}{cr} 
HSA & HSA \\
Purposes & Data \\
\hline
\end{tabular}

2) Increasing
accessibility

Increasing
accessibility
6) RESTRAINING $\cos T S$
7) PREVENTING RESOURCE DUPLICATION

4) Increasing continuity of care

6) IMP ROVEMENT IN QUALITY OF SERVICES

1) Improving health

1) IMP ROVING HEALTK

3) Increasing acceptability

5) Increasing guality

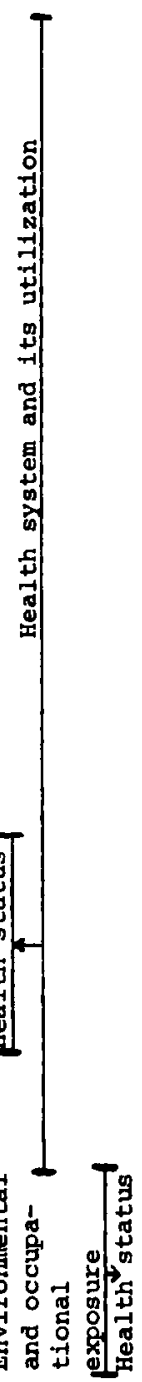


the population. Only the need for health education of the public seems to reflect it, and even that is oblique since the focus seemed to be more on health education to reduce overutilization of services. The findings did not cite any diseases or health conditions as problematic, nor did it imply that health services were so lacking, or so poor in quality, that a negative impact on the health of the population had resulted.

As the bottom line of the second column shows, only three of the national health priorities can be construed as remotely aimed at health improvement - prevention, health education, and quality of services, and even so, "quality" can mean a great many things other than clearly improved outcome in health status. The most notable thing in the second column is the fact that seven of the ten national health prtorities are related to cost containment.

Yet, as the third column shows, the HSAs are told their primary purpose is to improve health; their secondary purpose is to make health services even more ubiquitous, attractive, overutilized, comprehensive and expensive, i.e., "to increase accessibility, acceptability, continuity and quality" of services. And then they are told to restrain costs and prevent duplication.

Their instructions regarding data underscore the paradox. These local agencies, in areas with relatively small populations, are to answer questions that have been addressed by numerous studies at the National Institutes of Health and the National Center for Health Services Research, that is, they are to analyze the "environmental and occupational exposure factors affecting the health of the population" and "the effect the health care delivery system has on the health of the population", without collecting any data. (cf. Klarman, 1978) The existing health data available to them on local residents consists mainly of vital statistics, reportable diseases that have almost no connection to the hospital services for which they must plan, and mortality data that tells little of incidence, prevalence or etiology of the chronic diseases related to environment and occupation. Data available to them from the National Center for Health Statistics are based on national samples so small that they cannot be disaggregated for local areas, nor even for states.

On October 4, 1979, the Health Planning Law was amended to authorize the Secretary of HEW to: "collect data to determine whether the health care delivery systems meet or are changing to meet" the goals included in the plans of HSAs and state planning agencies; "prescribe the manner in which such data shall be assembled and reported"; and analyze the data. The amendments also added seven national health priorities, which seem to bear the following relationship to the findings that led to the original law, the other national health priorities, and the HSAs' purposes: 


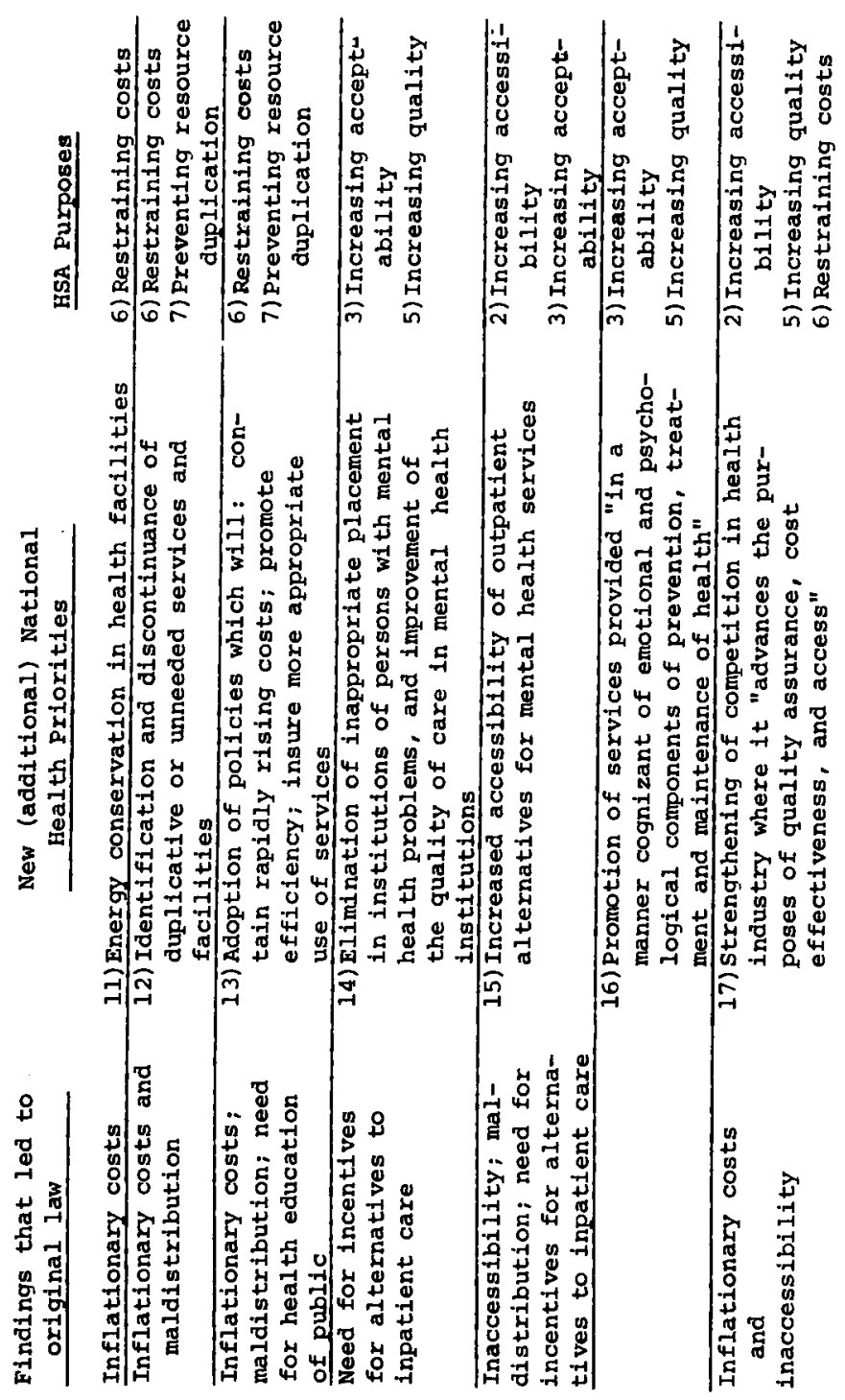


Priorities 12 and 13 are an expansion of priority 2, coordination and consolidation of hospital services; priorities 14, 15, 16 and 17 are related to priority 6 , improvement in quality. Although cost containment is implied in priorities $11,12,13$ and 17 , this is offset by the cost-generating implications of $14,15,16$ and 17 -- accessibility, acceptability and quality. It is also noteworthy that priorities 14,15 and 16 are the only ones that address a particular health status condition -- mental health. And not only do the new priorities give further evidence of what has been called the "schizophrenia of the feds" regarding health status and costs, but they introduce a new paradox unrelated to health status -- the "strengthening of competition" while consolidating services and preventing resource duplication.

\section{Health Status and Public Policy -- Blaming the Victim}

Economic and social class factors related to lifestyle, nutrition, environment and occupation are the major predictors of health status. A relatively small proportion of the variance in health status is attributable to the medical care system in this country. (cf. Fuchs, 1974; Knowles, 1977; Leveson, 1979; McKinlay and McKinlay, 1977; Rice, 1976). This fact has led to a new form of blaming the victim (cf. Crawford, 1977). Proponents of the new "holistic health" and "wellness" 1deologies are sometimes reminiscent of fundamentalist preachers in suggesting that those who become $i l 1$ must not have been living right. Insurance companies publish full-page ads in national magazines explaining why health care costs are skyrocketing. These depict people sitting in their living rooms watching television and snacking, in the park playing bail and drinking beer with paunchy friends on weekends, and working at their desks after II p.m. These appear to be among the things John Knowles, M.D., a prominent figure in health policy-making until his recent death (at age 52, of cancer) has described on national television and in a number of mass publications as the "personal misbehavior" responsible for health problems.

Making people feel responsible for their own behavior is good psychology; it helps to bring about the desired results. But it is poor policy-making and irresponsible governing to implement no incentive or disincentive system to elicit that desired behavior. It can reasonably be argued that those in government who hold the public responsible are, themselves, abrogating responsibility in public service (cf. Etzioni, 1977).

To address the health status problems related to consumer lifestyle, policy-makers must find ways to limit the availability and accessibility of the products in question (e.g.., tobacco, 
alcohol, non-nutritious foods), making them just difficult enough to obtain to somewhat reduce the demand, which would then reduce the supply. The related industries must then be encouraged and assisted in diverting to more socially beneficial products. The less beneficial must again be made slightly more unavailable, and so on. There must be a fine tuning and gradual adjustment throughout the process, to assure that it is always short of coercion and diminishing returns in the social system. There would appear to be a great deal of latitude for public policy between the one extreme of making something illegal, which can be disruptive to the economic system and lead to a black market, and the other extreme of letting industry dictate public policy. There has been a tendency toward the latter extreme in this country.

Recent studies have shown that the tobacco industry has benefitted even from ostensibly anti-smoking governmental actions. When broadcasters were prohibited from advertising cigarettss they were also freed of the obligation to broadcast anti-smoking messages, and smoking increased; the ban on broadcast advertising kept new cigarette firms out and permitted the six major firms to control over 998 of the market (cf. Doron, 1979). Furthermore, policy that protects the tobacco industry on the grounds that numerous jobs are involved and the economy of large regions that would otherwise be in poverty, and simultaneously castigates the smokers whose purchases assure that those people are fed, is policy without credibility (cf. Markle and Troyer, 1979).

This paper will not address the deficiencies of federal policy in regard to health status problems connected to environmental, industrial, and occupational factors. Those may well be the major health status problems, but health planning agencies cannot really be expected to deal with them. The Congressional Record of July 7,1978, shows that Congress is attempting to provide HSAs with a "clearer delineation of intended scope" and wished to direct them away from "amorphous areas" such as "air quality ," but some HSAs are objecting to this directive (cf. Higgins and Philips, 1979). They may wish to deal with these issues in general terms, but the chances that HSAs will point fingers at major industries responsible for health problems is minimal, given the fact that these politically vulnerable agencies are reluctant even to name the superfluous hospitals that need to close (Huppert et al., 1979).

\section{Health Care Overutilization - Blaming the victim}

Much of the literature implies the public is replete with hypochondriacs, overutilizers and abusers of the health care system. In reality, many of the annual check-ups, Pap smears, 
and so on, that are now deemed inappropriate for low-risk persons, were check-ups everyone was urged to get in the recent past. People who were compliant are now told they abused the system. The patient only initiates contact with the threshhold of the health care system and, after that, the drugs, the return visits, the hospital admission, the surgery, are all at the behest of the physician gatekeeper (cf. Fuchs, 1974; Ginzberg, 1978; Klarman, 1978; Stone, 1979).

People are now told they should get second opinions before undergoing any surgery, since research has shown that will reduce the amount of unnecessary surgery. When the second opinion differs from the first, a tie-breaking third must be sought. But getting a second or third opinion increases the number of initial visits to a doctor's office (the second and third doctor), so that statistic may increase and the so-called "worried well" again faulted for overutilization.

\section{Cost Containment and Health Planning}

Over the last ten years, the cost of hospital care has risen more than twice as fast as the total cost of living (cf. U.S. DHEW, 1978). As Sally Berger (1978), Chairman of the National Council on Health Planning and Development, has stated, health planners need a policy that articulates their mission: "to contain costs without detriment to health". Foisting health status problems onto health planning agencies funded at less than 50 cents per capita inpedes planners' ability to focus effectively on problems in the health care system related to cost containment. Health care providers struggling for individual economic survival, prestige and prosperity in an industry that needs to retrench would not be averse to having planning agencies diverted from cost containment into finding more patients for their services, particularly in they are patients who can be blamed for their own illnesses and for any ineffectiveness of treatment.

Virtually all attempts to resolve problems of health care financial inaccessibility have resulted in greater benefits to providers than to consumers. Medicare and Medicaid had unintended and unanticipated incentives to provider-induced overutilization that have now struck legitimate fear into the hearts of advocates of national health insurance (cf. Newhouse et al., 1977). Policymakers mave learned that programs extending even parsimonious payment for what were intended to be the clearest cut cases of need, have inevitably offered undue and unforeseen incentives to providers of care: "Rationing of health care", a phrase now being used by policy-makers, may already be occurring. Holding the line on government spending for health care, while the cost of health 
services steadily increases, means that fewer persons receive fewer services for those dollars being, held constant.

Yet there is no real constituency for cost containment. In 1977, 70 of personal health care expenditures, and 94 of hospital expenditures, were covered by third-party insurers. Governmentsupported programs paid 408 of all personal health care, and 558 of hospital care (cf. U.S. DHEW, 1978). These costs are passed on to the individual taxpayer and the payer of insurance premiums, but the taxpayer is seldom aware of how much of his or her taxes are earmarked for health care, and the impact on individual premium payers has been greatly mitigated by the fact that employers have been paying an ever-increasing proportion of these premiums. It is a basic social fact that spreading any cost burden more evenly reduces the likelihood that anyone will be affected enough to care about the cost (cf. Hiatt, 1975).

The National Health Planning Law states that the majority of members of the HSA's governing body shall be consumers of health care who are not providers, the intent being to prevent provider domination of health planning. "Major purchasers of health care" are mentioned last in a list of consumer types, and insurers, even though they clearly have a vested interest in containing costs, are specifically deemed "provlders". It has not been made sufficiently clear that the "consumer" is meant to be someone who has as strong an interest in and knowledge about restraining the health care system as providers of health care have interest in and knowledge about expanding it. And this consumer representative should have some political clout equal to that of the health providers. Such consumers may be the employers who pay large premiums for group insurance as part of the fringe benefits offered to employees. Individual premium payers do not have enough of a stake in cost containment to warrant committing themselves to it, they cannot sit on health planning boards and councils on company time as representatives of large employers can, and they cannot provide the countervailing balance to provider interests that industry can.

Organized labor is coming to realize that its members are not eager to gain greater health benefits at the cost of net loss in real earnings (cf. Council on Wage and Price Stability, 1976). Labor organizations are now specified as "major purchasers" of health care in new amendments to the health planning law. Nationwide the number of health sector jobs to be lost if cost-containment measures are taken is not likely to be prohibitive, although the potential loss of jobs due to hospital closure looms exceptionally large in New York City politically and is a highly publicized and volatile issue there. 
Labor-management coalitions are forming to take a more active role in health care cost containment and may prove to be a potent force (cf. Goldbeck, 1978).

\section{Implementation of Plans}

The only legally effective tool that HSAs have to implement cost containment plans is the Certificate of Need (CN). State laws specify that health facilities wishing to expand their buildings or services must apply for a CN. HSAs tend to devote one-quarter to one-half of their staff resources to reviewing these applications and they recommend approval or disapproval to the statewide Health coordinating council which, in turn, makes a recommendation to the state agency which is legally authorized to grant the $C N$. Federal monies are withheld from facilities violating state cN laws.

HSAs tend to recommend approval, but rarely because of "need", more commonly because any new service or building is a clear-cut addition to that community, whether or not it is needed, or adequately or appropriately utilized. It provides jobs, if nothing else. If it is disapproved for reasons of cost containment, the money saved is not money the community gets to spend on some other, more necessary service in its own area exclusively; the savings are spread across the country. So the indisputable logic is, "If we put it here, whatever the gain in service, it's totally our gain and the cost is only fractionally ours. If we keep it out, the savings are fractionally ours, and the service gain is zero to everyone."

This logic and the power of individual providers has meant that unless there are competing $\mathrm{CN}$ applications, planners reviewing these applications rarely have to justify approval but are nearly always forced to justify denial. The burden of proof is not on the applicant and "Certificate of Need" has proved to be a misnomer; it might more accurately be termed a "Certificate of Acquiescence".

$\mathrm{CN}$ laws are only designed to limit or control growth and, even so, most studies indicate they have had little success (cf. Ginzberg, 1978; Klarman, 1976 and 1978; Wendling, 1978). CN applications must be initiated by providers, and the planners' role is reactive. $\mathrm{CN}$ does not provide an implementation tool for planning initiatives directed at contraction of the health care industry - consolidation and closure of unnecessary facilities and services. The potential tools for contraction are not in the hands of HSAs, but rest with state agencies, which license health facilities, make the ultimate $C N$ decisions (sometimes using HSA staff analyses that were ignored by provider-influenced HSA boards), set 
the reimbursement rates that third-party payers are allowed to pay hospitals, and pass regionalization regulations (cf. Altman, 1978). state rate-setting is relatively new, exists in only a few states, and is usually limited to Medicaid and/or Blue Cross reimbursement. However, New Jersey has a new law which will permit the state planning agency to set rates for all third-party payers.

The National Guidelines for Health Planning referred to earlier are intended to be used to effect contraction, consolidation and closure. They were late and limited because they had to run the gauntlet. As sound, well-documented and well-established as these standards were, the provider hue and cry resounded throughout the nation. In 77 days of public comment 55,000 communications were received and five public hearings were held. Some of the standards had to be lowered, and federal planners may be reluctant to undergo another such barrage in the foreseeable future. But state and HSA planners need many more such criteria and standards in order to function effectively. In New Jersey state planners had written state regionalization regulations and plans around most of the above standards and criteria a year before the federal guidelines appeared. Other states may have to develop and pass regulations with only covert support from federal agencies.

The last paradox of health planning is that the current antitaxation/anti-government movement is not likely to distinguish between governmental units which provide services and pass regulations which increase costs, and those agencies which are designed to reduce unnecessary services and restrain costs through regulation.

Summary

A health care cornucopia led to runaway inflation in costs. The National Health Planning Law was originally intended to control and curtail the proliferation of health services, distributing them more rationally and economically. But the law led to the establishment of health planning agencies that are expected to (1) grapple with the causes of disease in small areas for which data do not exist and cannot be collected; (2) improve health status by planning for services which do not significantly affect the health status of a population; (3) improve the services while reducing their cost; and (4) keep the services to a minimum by persuading local power-wielders that they should be altruistic, foregoing services in their own area so that taxpayers in 199 other areas of the country can benefit. Meanwhile, real health status problems are being attributed to bad habits and immorality of individuals using products that are manufactured, distributed and widely advertised under an industry-protective public policy. 
If health planring agencies are to justify their existence they must be allowed to focus on restraining, converting, consolidating and closing excess health services. They must develop a constituency for cost containment. They must have planning criteria and standards that become legally binding through state and federal legislation.

\section{References}

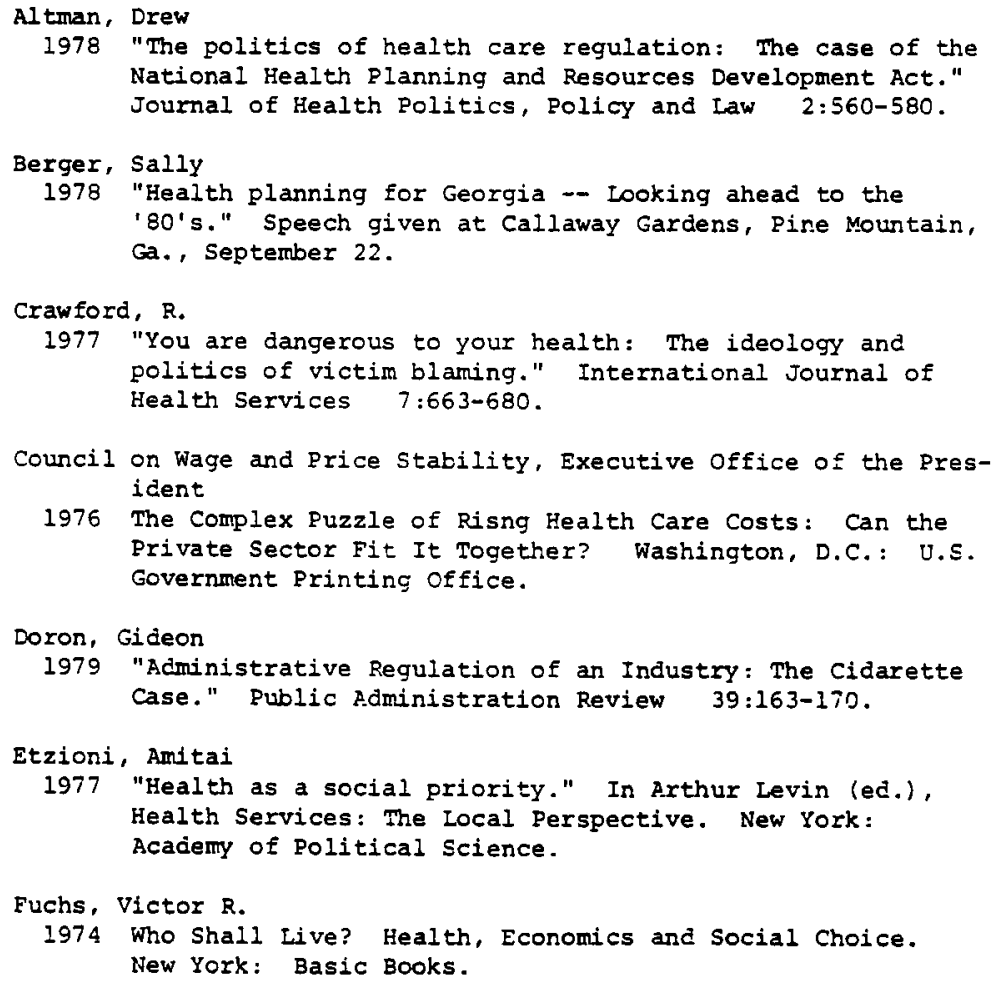




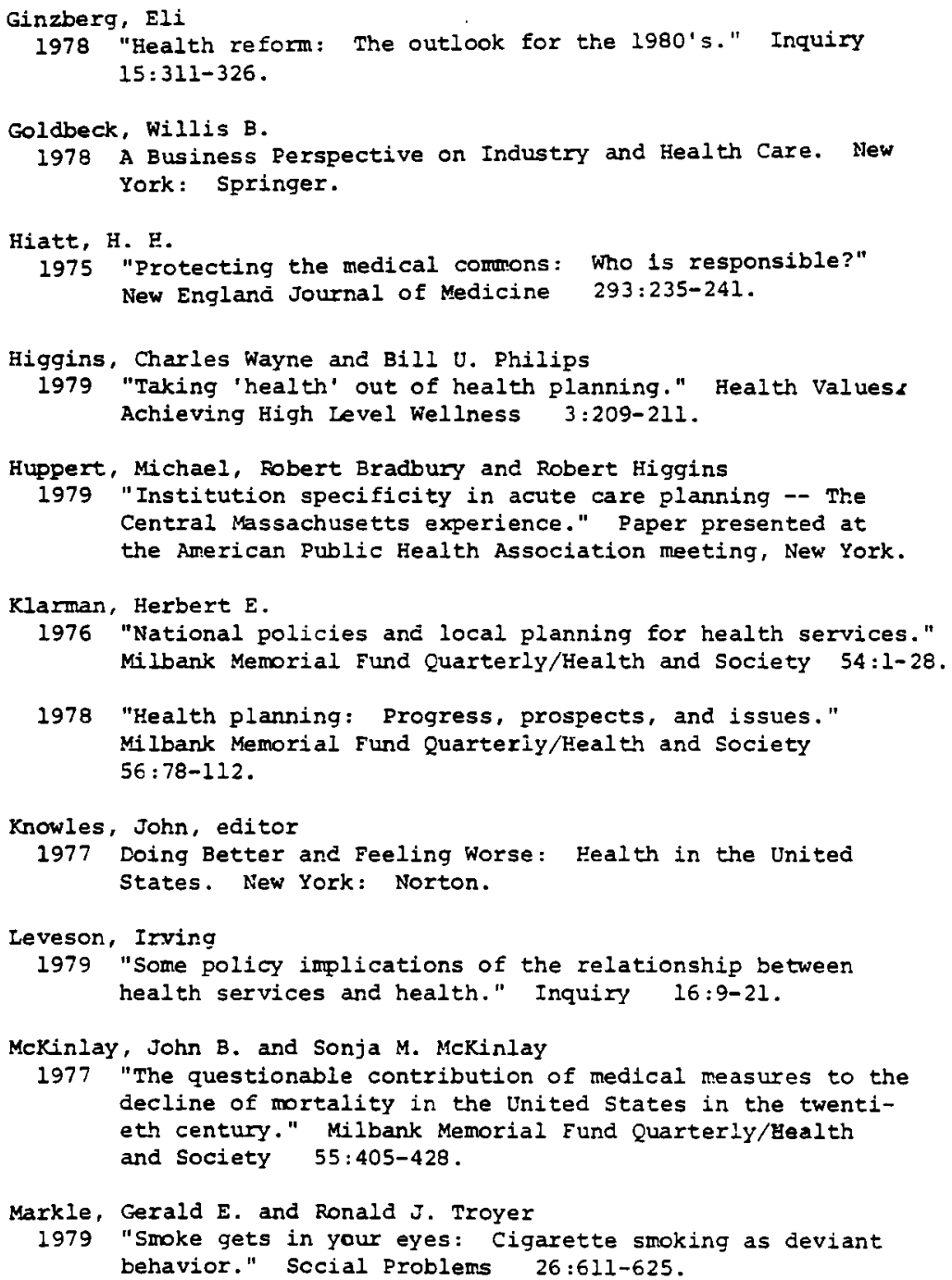


Newhouse, Joseph P., Charles E. Phelps and William B. Schwartz

1977 "Policy options and the impact of national health insurance." In Robert H. Haveman and Julius Margolis (eds.), Public Expenditure and Policy Analysis, 2nd ed. Chicago: Rand McNally.

Rice, Dorothy P.

1976 "The American medical economy: Problems and perspectives." Journal of Health Politics, Policy and Law 1:151-172.

Stone, Deborah A.

1979 "Physicians as gatekeepers: Illness certification as a rationing device." Public Policy 27:227-254.

घ.S. Department of Health, Education, and Welfare 1978 Health: United States 1978. Hyattsville, Md.: National Center for Health Statistics and National Center for Eealth Services Research.

Wendling, Wayne

1978 "A reexamination of the impact of certificate-of-need laws." In Jack L. Werner and Jacqueline R. Leopold (eds.), Socioeconomic Issues of Health 1978. Monroe, Wisc.: American Medical Association. 